Article

\title{
Study on ASJ Cutting of TC18, Based upon Multivariate Nonlinear Regression and SA-BP-AGA
}

\author{
Jie Lin ${ }^{1}$, Xin Zhou ${ }^{1}$, Hui Zhang ${ }^{1,2}$, Fengchao Wang ${ }^{1}$, Qiwen $\mathrm{Xu}^{1}$ and Chuwen Guo ${ }^{1, *}$ \\ 1 School of Electrical and Power Engineering, China University of Mining and Technology, Xuzhou 221116, \\ China; TS17130003A3@cumt.edu.cn (J.L.); jianniang_zhouxin@163.com (X.Z.); cumthui@126.com (H.Z.); \\ wfc0317@163.com (F.W.); xqw0703@163.com (Q.X.) \\ 2 Xuhai College, China University of Mining and Technology, Xuzhou 221116, China \\ * Correspondence: cwguo@cumt.edu.cn
}

Received: 19 May 2019; Accepted: 12 June 2019; Published: 13 June 2019

check for updates

\begin{abstract}
TC18 titanium alloy has been widely applied, but is considered as a difficult machining material. Taking the kerf angle as the quality criterion, this paper studied the cutting performance of TC18 by the use of an abrasive slurry jet (ASJ), based upon multivariate nonlinear regression and SA-BP-AGA. Cutting experiments were carried out according to the Taguchi orthogonal method. The experimental factors included traverse speed, standoff distance, pressure and slurry concentration, with five levels set, respectively. Meanwhile, a characterization method of the major influencing factors was proposed. A multiple nonlinear regression model and a back propagation artificial neural network (BP) prediction model, based on adaptive genetic algorithm (AGA), were established. The reliability was verified by statistics equations for the 22 groups of the fitting or training model and the three groups of experimental results. The BP-AGA and Simulated annealing algorithm (SA) were used to form a set of prediction optimization systems, called integrated SA-BP-AGA. Finally, the results showed that the main factor influencing the kerf angle is the slurry concentration. BP-AGA is easier to model, offers better robustness and is more accurate than a multivariate nonlinear regression model. The best kerf angle can be predicted by the integration system. The study results can improve the performance for the machining of TC18 by ASJ.
\end{abstract}

Keywords: ASJ cutting; retardation coefficient; SA-BP-AGA; TC18

\section{Introduction}

Titanium alloy TC18 (Ti-5Al-5Mo-5V-1Cr-1Fe) possesses the common excellent performance of both alpha phase and beta phase titanium alloy, such as high strength to weight ratio, high toughness, high hardness, high corrosion resistance, being non-magnetic and so on, with a new style alloy (alpha + beta). It has been widely used in aviation, biomedical, automotive fields, etc. [1,2]. However, there exist enormous challenges for traditional machining approaches due to its properties, including poor heat transfer performance, work-hardening and unstable chemical reaction, and deformation under high temperature conditions, which tends to cause serious tool wear, even much lower durability and shorter life than expectancy [3-5]. Moreover, some researches showed that the quality of the machined surface of the work piece has significant influence on its mechanical properties, especially upon fatigue properties [6-8]. To address these issues, some researchers used an improved genetic algorithm to optimize the milling parameters of TC18, and studied the forging process parameters of TC18 based upon the BP neural network, but it did not overcome the negative effect of the poor property of TC18 on the quality of the traditional processing technology, such as the heat affected zone, etc. $[9,10]$. Therefore, there is an urgent need for an advanced processing method to solve various problems that arise in the processing of TC18. 
ASJ technology is one of the fastest growing and most advanced non-traditional processing technologies. It has the advantages of no thermal effects, no residual stress, good incision quality, high applicability of materials, being environment friendly and highly competitive in material processing [11]. Wang studied the mechanism of kerf width and kerf angle formation during abrasive water jet machining [12]. Azmir used the Taguchi experimental method and variance analysis to study the influence of processing parameters on the kerf angle upon the cutting of glass/epoxy composite laminate, and concluded that the type of abrasive is the most important controlling factor [13]. Alberdi established a mathematical model based on pressure, the mass flow of the abrasive, target distance and transverse velocity processing parameters, which is used to predict the profile produced by AWJ cutting 1075-T651 [14]. Feng used numerical simulations and experiments, concluding that the jet with the added polymer has better stability in air [15]. Wang found that adding high polymer to the abrasive slurry to cut stainless steel would have better processing performance [16]. Just as traditional machining relies on computer optimization control and an optimization of processing efficiency [17-19], advanced computer algorithms can also be used to optimize the processing parameters of an abrasive water jet in order to obtain high-quality products. Azlan used an integrated system of SA and GA algorithms to optimize the parameters of the abrasive processing process [20]. However, it depends on a great multivariate nonlinear regression model which is difficult to obtain. By considering the diameter of the focused nozzle and controllable process parameters such as work pressure, traverse speed and abrasive flow rate, Srinivasu modeled the artificial neural network to predict the depth of cut in the AWJ process, and also used a genetic algorithm to find out the optimal parameters combination [21]. However, the accurate ANN (artificial neural networks) prediction modeling was constructed directly with enormous work and difficulty.

In order to study the effect of processing parameters on TC18, we used Taguchi's orthogonal method to carry out the experiments. To optimize the machining process by ASJ for TC18, and at the same time taking into account the stability of the jet pressure in the experiment, we provided some new measures to analyze the experimental data. Firstly, a multivariate nonlinear regression model was established, and the reliability of the prediction model was verified by using a mathematical statistics formulae (MAPE, MSE and $\mathrm{R}^{2}$ ) and some specific experimental data. Based on the verification results, the model was only used to determine the main influencing factors of the experiment, which indicated that Azlan's method [20] was not applicable here. We comprehensively utilized the good methods proposed by Azlan [20] and Srinivasu [21], meanwhile avoiding the restrictive conditions in [20] that it must rely on a great nonlinear prediction model, and solved the difficult problem of directly establishing the neural network prediction model in [21]. A back propagation artificial neural network (BP) prediction model, based on adaptive genetic algorithm (AGA) was established, and of which (BP-AGA) the validation was checked by using the same method as above. Then this study compared the multiple nonlinear regression method with the neural network method optimized by the adaptive genetic algorithm. It is found that BP-AGA is easier to model, offers better robustness and is more accurate. Finally, the BP-AGA and simulated annealing algorithm (SA) optimization technology were used to form a set of prediction systems, called integrated SA-BP-AGA. Through this integrated system, the best kerf angle and the parameters affecting the kerf angle were obtained. The study results can improve the performance for TC18 machining by ASJ.

\section{Experiment}

\subsection{Experimental System}

The experiment was carried out on the DWJ1313-FC abrasive jet cutting system (DARDI, Nanjing, China) at the Water Jet Research Center of the China University of Mining and Technology, and the set of equipment is shown in Figure 1. 


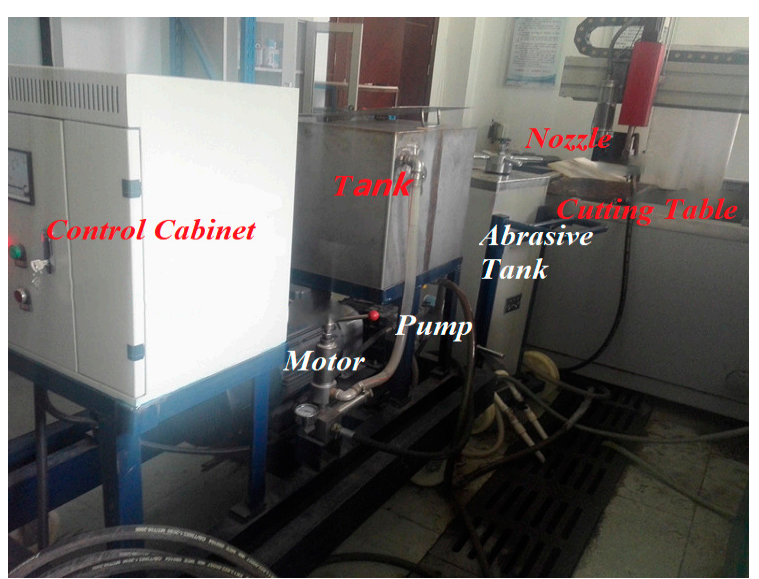

Figure 1. DWJ1313-FC Abrasive Jet Machining system.

As shown in Figure 1, the experimental equipment consists of a control cabinet, CNC (computerized numerical control) cutting table, booster pump, the water tank, an abrasive tank, etc. Firstly, the working pressure is set by the control cabinet, and then the booster pump is started to force the polyacrylamide (PAM) slurry in the water tank flow into the abrasive tank at high speed, and then mix with the abrasive particles to form the abrasive slurry high-speed fluid. Then the steady jet is polymerized by the jet nozzle on the numerical control cutting platform. Finally, the cutting platform can be activated, and the nozzle will carry out the cutting experiment according to the planning road path.

\subsection{Experimental Scheme}

As shown in Figure 2, there are many processing parameters to be set in the ASJ cutting experiment. In this experiment, the effects of traverse speed, standoff distance, system pressure and slurry concentration on the cutting quality characteristics (the kerf angle), are studied. The kerf angle indicates the inclination of the cutting wall. To solve the problems of expensive costs and inefficiency caused by the full-factor experimental method, we adopted the Taguchi orthogonal theory to carry out experiments [22]. Five levels were set for each variable, as shown in Table 1, and other processing parameters were kept constant for all cuts, as shown in Table 2. Based on the same experimental system, Wang [12] provided a reference for the experimental processing parameter design of this paper.

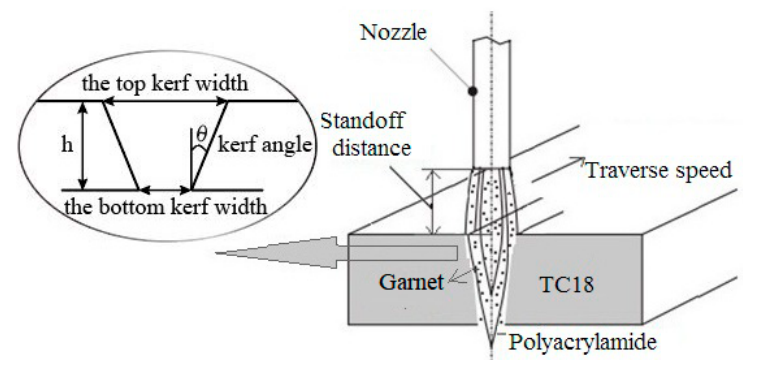

Figure 2. Processing principle schematic.

Table 1. Variable parameters and their levels.

\begin{tabular}{ccccccc}
\hline Number & Variables & L1 & L2 & L3 & L4 & L5 \\
\hline 1 & Traverse speed V & 30 & 40 & 50 & 60 & 70 \\
2 & Standoff distance H (mm) & 0.5 & 1 & 1.5 & 2 & 2.5 \\
3 & Slurry concentration C & 0 & 0.05 & 0.1 & 0.15 & 0.2 \\
4 & System pressure P (MPa) & 18 & 22 & 26 & 30 & 34 \\
\hline
\end{tabular}


Table 2. Constant Parameters.

\begin{tabular}{cc}
\hline Invariables & Values \\
\hline Material size & $200 \times 30 \times 5\left(\mathrm{~mm}^{3}\right)$ \\
Nozzle diameter & $1.0(\mathrm{~mm})$ \\
Volume fraction of abrasive & $20 \%$ \\
High Polymer & PAM \\
Average diameter of abrasive & $0.27(\mathrm{~mm})$ or $80($ mesh $)$ \\
Abrasive material type & garnet \\
Angle of influence & 0 (degree) \\
\hline
\end{tabular}

\subsection{Experimental Results}

This experiment followed the L25 $\left(5^{4}\right)$ orthogonal experiment table designed by MINITAB 17 software. The actual processed data and the measured characterization data were shown in Table 3. The kerf width was measured with an OLYMPUS DSX510 Microscope (Olympus, Tokyo, Japan). For high-quality image acquisition, we used an external 10× objective lens and an internal default $50 \times$ eyepiece combination. Then, through the DSX software system, we set the focal length to $1 \times$, then set the acquisition mode to a 3D bright field, and set the image stitching overlap ratio to $20 \%$, and finally set the acquisition area to $10 \mathrm{~mm} \times 3 \mathrm{~mm}$. After the automatic acquisition and splicing were completed, the geometric measurement mode in the DSX510 software measurement module was selected to measure the kerf width in the high quality image. In order to reduce the error caused by the measurement, the top kerf width and the bottom kerf width corresponding areas of the same cut sample, were respectively measured 25 times, and the average values were taken as their final measurement results. Image measurement is shown in Figure 3.

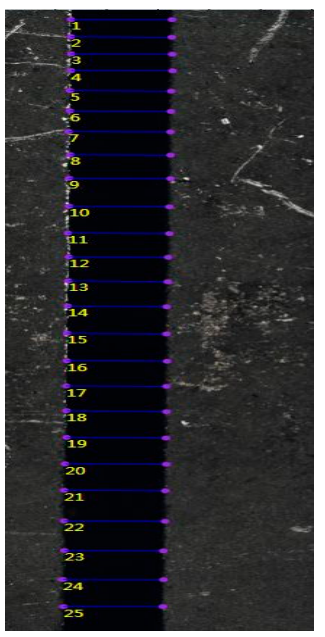

(a)

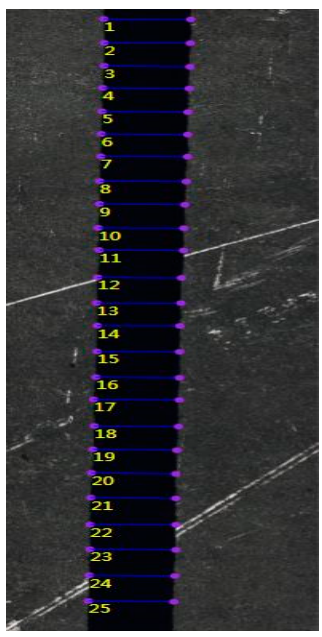

(b)

Figure 3. Measure mode diagram. (a) Top kerf width; (b) bottom kerf width. 
Table 3. The experimental data for model constructions.

\begin{tabular}{|c|c|c|c|c|c|c|c|c|}
\hline \multirow[b]{2}{*}{ NO. } & \multicolumn{5}{|c|}{ Operating Variables } & \multicolumn{3}{|c|}{ Result } \\
\hline & $\mathbf{V}$ & $\mathbf{H}$ & $\mathrm{C}$ & $\mathbf{P}$ & Actual P & $\begin{array}{c}\text { Top Kerf } \\
\text { Width (mm) }\end{array}$ & $\begin{array}{l}\text { Bottom Kerf } \\
\text { Width (mm) }\end{array}$ & $\begin{array}{c}\text { Kerf } \\
\text { Angle }\left(^{\circ}\right)\end{array}$ \\
\hline 1 & 1 & 1 & 1 & \multirow{5}{*}{1} & 18.1 & 0.880234 & 0.51703 & 4.1547 \\
\hline 2 & 2 & 2 & 4 & & 18.4 & 0.901138 & 0.752207 & 1.7061 \\
\hline 3 & 3 & 3 & 2 & & 18.3 & 0.940592 & 0.820456 & 1.3764 \\
\hline 4 & 4 & 4 & 5 & & 17.8 & 0.896659 & 0.708886 & 2.1507 \\
\hline 5 & 5 & 5 & 3 & & 17.9 & 1.013852 & 0.867836 & 1.6727 \\
\hline 6 & 1 & 4 & 3 & \multirow{5}{*}{2} & 22.1 & 1.027128 & 0.852151 & 2.0043 \\
\hline 7 & 2 & 5 & 1 & & 22.2 & 1.003986 & 0.516018 & 5.574 \\
\hline 8 & 3 & 1 & 4 & & 21.7 & 0.913358 & 0.732508 & 2.0715 \\
\hline 9 & 4 & 2 & 2 & & 22.8 & 0.909006 & 0.77915 & 1.4877 \\
\hline 10 & 5 & 3 & 5 & & 22.4 & 0.908018 & 0.767484 & 1.61 \\
\hline 11 & 1 & 2 & 5 & \multirow{5}{*}{3} & 25.9 & 0.901708 & 0.785861 & 1.3273 \\
\hline 12 & 2 & 3 & 3 & & 25.9 & 0.940733 & 0.59944 & 3.9049 \\
\hline 13 & 3 & 4 & 1 & & 26.1 & 0.958826 & 0.514941 & 5.0732 \\
\hline 14 & 4 & 5 & 4 & & 26.7 & 0.999784 & 0.786822 & 2.4389 \\
\hline 15 & 5 & 1 & 2 & & 26.8 & 0.925032 & 0.767567 & 1.8038 \\
\hline 16 & 1 & 5 & 2 & \multirow{5}{*}{4} & 30.5 & 1.048323 & 0.919693 & 1.4737 \\
\hline 17 & 2 & 1 & 5 & & 30 & 0.923354 & 0.768629 & 1.7725 \\
\hline 18 & 3 & 2 & 3 & & 30.6 & 0.979514 & 0.822616 & 1.7973 \\
\hline 19 & 4 & 3 & 1 & & 30.4 & 0.946768 & 0.532342 & 4.7381 \\
\hline 20 & 5 & 4 & 4 & & 31.6 & 0.996658 & 0.798935 & 2.2646 \\
\hline 21 & 1 & 3 & 4 & \multirow{5}{*}{5} & 34.8 & 1.027287 & 0.864021 & 1.8702 \\
\hline 22 & 2 & 4 & 2 & & 33.5 & 0.965137 & 0.852903 & 1.2859 \\
\hline 23 & 3 & 5 & 5 & & 34.1 & 0.991862 & 0.782701 & 2.3954 \\
\hline 24 & 4 & 1 & 3 & & 35.4 & 0.927152 & 0.855971 & 0.8156 \\
\hline 25 & 5 & 2 & 1 & & 33.9 & 0.960782 & 0.54892 & 4.709 \\
\hline
\end{tabular}

The inclination of the kerf is defined as:

$$
\mathrm{q}=\tan ^{-1}\left(\frac{\mathrm{W}_{\mathrm{top}}-\mathrm{W}_{\mathrm{bottom}}}{2 \mathrm{~h}}\right)
$$

where, $\theta, W_{\text {top }}, W_{\text {bottom, }}$ and $h$ are the kerf angle, the thickness of the cutting specimen, the top kerf width, and the bottom kerf width, respectively, as shown in Figure 2.

\section{Predictive Model of Kerf Angle based on Multivariate Nonlinear Regression Modeling}

\subsection{Methodology}

Due to the slight fluctuation of the instability of the jet pressure during the real processing, the fluctuation error can be quantized by the mean relative level error function (MRLE).

$$
\text { MRLE }=\frac{1}{\mathrm{~d}} \sum_{\mathrm{i}}\left(\frac{\left|\mathrm{t}_{\mathrm{i}}-\mathrm{o}_{\mathrm{i}}\right|}{\mathrm{n}}\right) \times 100 \%
$$

where, $\mathrm{d}$ is the tolerance among the adjacent levels, $t_{i}$ is the actual experiment value of the group $i, o_{i}$ is the designed value or the predictive value, $\mathrm{n}$ is the number of designs at the same level. 
The Mean relative pressure level error calculated by the above Equation (2) is shown in Figure 4. In Figure 4, the corresponding value of $Y$ is the decimal form of MRLE. It can be seen from the diagram that the maximum average relative error is $15.5 \%$. Therefore, the commonly used analysis method-single factor multivariate variance based upon the Taguchi orthogonal method cannot be applied in this article.

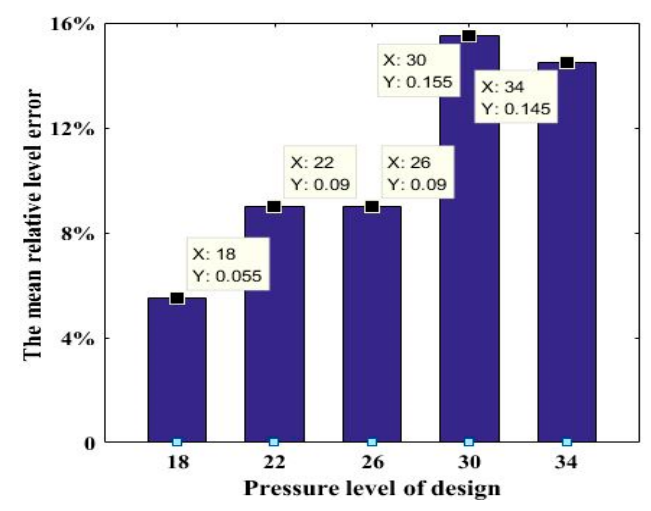

Figure 4. Mean relative pressure level error.

Therefore, we proposed a new idea to deal with this kind of situation. First of all, through multivariate nonlinear regression methods, the fitting was performed on the actual jet pressure values in all the odd groups and all the even numbers except $(18,22,24)$ in Table 3 . Then, the fitting degree of the regression equation was determined based on the multivariate correlation coefficient $R$, after which the reliability of the prediction model was verified by mathematical statistics formulas with the 22 groups' modeling data and the remaining three groups' data of experiments. These formulae included the determination coefficient $\left(\mathrm{R}^{2}\right)$, mean squared error (MSE) and the mean absolution percentage error (MAPE).

$$
\begin{gathered}
\mathrm{R}=\frac{\sum\left(\mathrm{t}_{\mathrm{i}}-\overline{\mathrm{t}}\right) \sum\left(\mathrm{o}_{\mathrm{i}}-\overline{\mathrm{t}}\right)}{\sqrt{\sum\left(\mathrm{t}_{\mathrm{i}}-\overline{\mathrm{t}}\right)^{2} \sum\left(\mathrm{o}_{\mathrm{i}}-\overline{\mathrm{t}}\right)^{2}}} \\
\mathrm{R}^{2}=1-\left(\frac{\sum_{\mathrm{i}}\left(\mathrm{t}_{\mathrm{i}}-\mathrm{o}_{\mathrm{i}}\right)^{2}}{\sum_{\mathrm{i}}\left(\mathrm{o}_{\mathrm{i}}\right)^{2}}\right) \\
\text { MSE }=\left(\frac{1}{\mathrm{~N}} \sum_{\mathrm{i}}\left|\mathrm{t}_{\mathrm{i}}-\mathrm{o}_{\mathrm{i}}\right|^{2}\right) \\
\operatorname{MAPE}=\left(\frac{1}{\mathrm{~N}} \sum_{\mathrm{i}}\left|\frac{\mathrm{t}_{\mathrm{i}}-\mathrm{o}_{\mathrm{i}}}{\mathrm{t}_{\mathrm{i}}}\right| \times 100\right)
\end{gathered}
$$

where $\bar{t}$ is the average of the actual experiment value; $N$ is the total amount of participating in the calculation of runs.

Finally, partial derivatives of each processing variable of the established regression equation were calculated. Substituting the values of the processing variables in each group into the partial derivative equation, the slope of the aimed partial variable of the regression equation in each group coordinates was obtained, as described in Equation (7).

$$
\operatorname{Slope}_{(\mathrm{k})}=\left.\mathrm{f}_{\mathrm{k}}^{\prime}(\mathrm{V}, \mathrm{H}, \mathrm{C}, \mathrm{P})\right|_{\left(\mathrm{V}_{\mathrm{i}}, \mathrm{H}_{\mathrm{i}}, \mathrm{C}_{\mathrm{i}}, \mathrm{P}_{\mathrm{i}}\right)}
$$

where, Slope $_{(\mathrm{k})}$ is the slope of the equation about the $\mathrm{k}$ variable, $\mathrm{k}$ can be $\mathrm{V}, \mathrm{H}, \mathrm{C}$ or P. In addition, $\mathrm{V}_{\mathrm{i}}$, $\mathrm{H}_{\mathrm{i}}, \mathrm{C}_{\mathrm{i}}$ and $\mathrm{P}_{\mathrm{i}}$ are the values of group $\mathrm{i}$ in Table 3 , respectively. 
These comprehensive values of the slope of each variable can be figured out to characterize the sensitivity of the kerf angle to each processing variable, which are shown as the Equations (8)-(11).

$$
\begin{gathered}
\operatorname{Mean}\left(\mathrm{S}_{\mathrm{k}}\right)=\frac{1}{\mathrm{n}} \sum_{\mathrm{i}}^{\mathrm{n}} \operatorname{Slope}_{(\mathrm{k}) \mathrm{i}} \\
\mathrm{Ct}=\Delta \theta /\left(\frac{\Delta \mathrm{k}}{\mathrm{k}_{\max }-\mathrm{k}_{\min }}\right)=\frac{\Delta \theta}{\Delta \mathrm{k}} \times\left(\mathrm{k}_{\max }-\mathrm{k}_{\min }\right)
\end{gathered}
$$

In which,

$$
\frac{\Delta \theta}{\Delta \mathrm{k}}=\operatorname{Mean}\left(\mathrm{S}_{\mathrm{k}}\right)
$$

where, Mean $\left(S_{k}\right)$ is the mean of each variable's slope; $C t$ means that when the other variables are unchanged, the change of $\mathrm{k}$ relative to its own interval will theoretically cause the maximum change of $\theta$; and $\mathrm{k}$ represents one of the variables selected in the experiments.

$$
\mathrm{Cr}=\left|\frac{\theta_{\max }-\theta_{\min }}{\mathrm{Ct}}\right|
$$

where, $\mathrm{Cr}$ is the interval length of the actual kerf angle change divided by the $\mathrm{Ct}$ (in theory, the maximum change length of the $\mathrm{k}$ variable can cause the maximum change in the kerf angle). This also means that this $\mathrm{k}$ factor hinders the change of inclination caused by the change of the other factors through its own changes, which is called the retardation coefficient of $k$.

The smaller the retardation coefficient is, the more powerful the influence of $k$ is. The method was compared with the results of multiple variances, and it was found that when the $\mathrm{Cr}$ corresponding to the factor was less than 10, the factor had an important influence.

Through this method, the influence of factors can be sorted, and the main influencing factors are identified.

\subsection{The Regression Model of Kerf Angle}

What is given here mainly showed the transformation of the original data by us to complete the regression fitting. The mathematical model established in this paper is expressed as Equation (12), which is one of the commonly used fitting basic equations in the field of waterjet machining $[20,23,24]$.

$$
\theta=\mathrm{aV}^{\mathrm{q}} \mathrm{H}^{\mathrm{s}}\left(\mathrm{C}+\mathrm{C}_{0}\right)^{\mathrm{z}} \mathrm{P}^{\mathrm{u}} \mathrm{e}^{\prime}
$$

where, $\varepsilon^{\prime}$ is the experimental error, and $\mathrm{a}, \mathrm{q}, \mathrm{s}, \mathrm{C}_{0}, \mathrm{z}$ and $\mathrm{u}$ are pending parameters to be estimated by the experimental data.

Equation (12) can be linearized by performing a logarithmic transformation as follows:

$$
\ln \theta=\ln \mathrm{c}+\mathrm{q} \ln \mathrm{V}+\mathrm{s} \ln \mathrm{H}+\mathrm{t} \ln \left(\mathrm{C}+\mathrm{C}_{0}\right)+\mathrm{uln} \mathrm{P}+\ln \mathrm{e}^{\prime}
$$

The final Equation (13) can be written as:

$$
\hat{\theta}=\mathrm{aV}^{\mathrm{q}} \mathrm{H}^{\mathrm{s}}\left(\mathrm{C}+\mathrm{C}_{0}\right)^{\mathrm{t}} \mathrm{P}^{\mathrm{u}}
$$

The regression model for the kerf angle that has been determined, is as follows:

$$
\hat{\theta}=2.038 \mathrm{~V}^{0.0094} \mathrm{H}^{-0.0088}\left(\mathrm{C}+1 \times 10^{-5}\right)^{-0.0971} \mathrm{P}^{-0.0896}
$$


The multivariate correlation coefficient $\mathrm{R}$ is calculated as the linearized regression Equation (13), and $R=0.8316$, greater than 0.8 , which can be accepted. The rest of the mathematical statistics test is calculated according to Equation (15). Using the remaining 3 groups of experimental parameters to check the prediction accuracy of the equation, and quantified by statistical formulae $\mathrm{R}^{2}$, MSE, and MAPE. The results listed into the table 5 are $0.8383,0.6415$, and $69.4384 \%$, respectively. Although the mean absolute error percentage exceeds $20 \%$, indicating that the regression model prediction accuracy is not high, the coefficient of determination and the average error are both within acceptable limits, and the statistical result of training groups are $0.9558,0.3647$, and 19.5027 , which are listed into the Table 4 . So the training groups can be used to assess the influence of the four factors.

\subsection{Analysis of Main Influencing Factors}

By Equations (7) and (8), the slope of each variable is calculated and expressed in Figure 5.

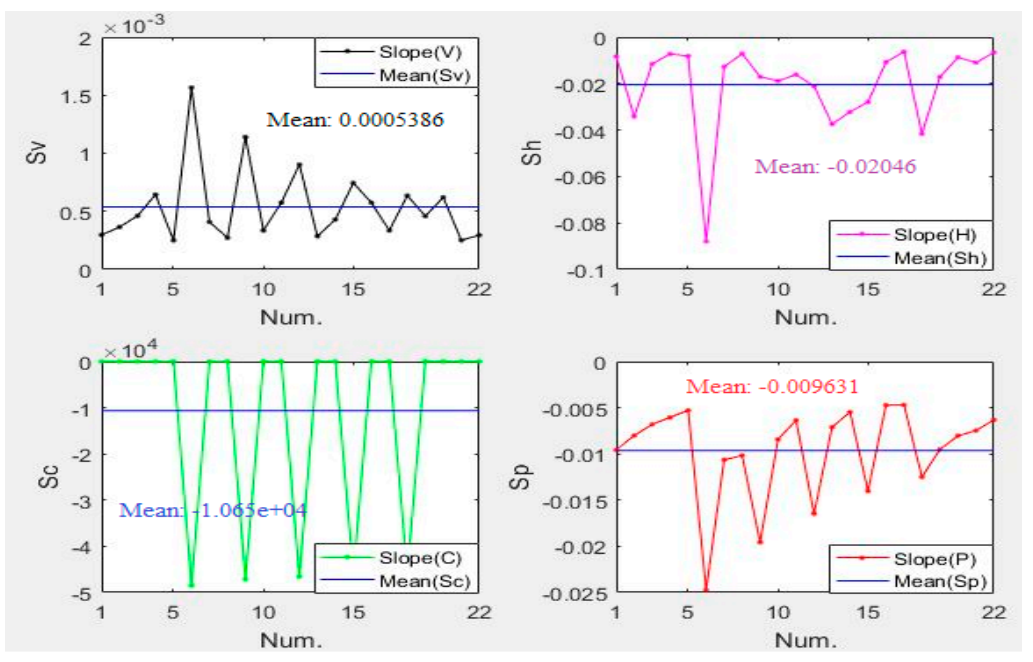

Figure 5. Slope (V, H, C, P).

As shown in Figure 5, it can be obviously observed that the slope fluctuation of the slurry concentration is particularly intense, and its absolute mean value is also large, which is several orders of magnitude larger than the other three variables. So a simple estimate can be obtained that the main influencing factor is C. By Equation (11), the Cr values of V, H, C and P are 228.77, 116.5388, 0.0025, and 32.61, respectively. It can be clearly known that $C$ has a significant influence, followed by $\mathrm{P}, \mathrm{H}$, and $\mathrm{V}$, which has little influence.

\section{Predictive Model of Kerf Angle Based on ANN-AGA}

It can be seen from the above calculation results that the multivariate nonlinear regression is not good at prediction. Therefore, a new prediction model is established.

\subsection{Methodology}

During neural network training, network structure parameters and initial thresholds and weights determine the training duration and network quality of the network to a large extent. Due to the nature of the "black box" of neural networks, it leads to blindness in debugging and low training efficiency.

However, by using the AGA method to find the optimal initial training thresholds and weights of the neural network, the blindness of debugging is reduced to a certain extent, the efficiency of network training is greatly improved, and the quality of the network is indirectly improved. Finally, the test results are analyzed by the same statistical formulae $\left(\mathrm{R}^{2}, \mathrm{MSE}\right.$ and MAPE).

An adaptive genetic algorithm optimizes the BP neural network flow as shown in Figure 6. 


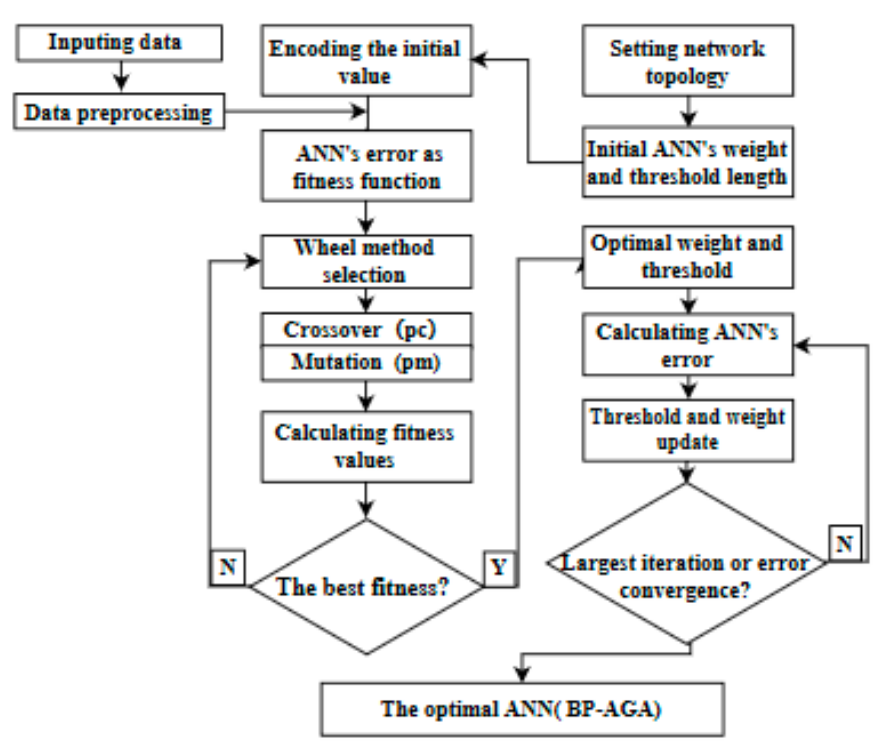

Figure 6. Back propagation-adaptive genetic algorithm (BP-AGA) structure schematic diagram.

After debugging the structure of neural network and random initial weights and thresholds, it is supplemented by the adaptive genetic algorithm to improve efficiency and quality. This genetic algorithm mainly includes chromosome coding, selection operation, mutation operation, crossover operation and fitness operation. Among them, the crossover ratio (pc) and the mutation ratio (pm) in the parameters of the genetic algorithm play very important roles in the performance of the algorithm. If the fixed pc and pm values are adopted, it is difficult to adapt to the change of population, and sometimes leads to the evolution of the past. In this paper, an adaptive algorithm based on Srinvivas is proposed. The $\mathrm{pc}$ and $\mathrm{pm}$ in the algorithm can change automatically with fitness values, which can maintain group diversity and ensure convergence, as shown in Equation (16) below.

$$
\begin{aligned}
& \mathrm{pc}=\left\{\begin{array}{cl}
\mathrm{pc} c_{\max }-\frac{\left(\mathrm{pc}_{\max }-\mathrm{pc} c_{\min }\right)\left(\mathrm{f}_{\max }-\mathrm{f}^{\prime}\right)}{\mathrm{f}_{\max }-\mathrm{f}_{\text {avg }}}, & \mathrm{f}^{\prime} \geq \mathrm{f}_{\mathrm{avg}} \\
\mathrm{pc} c_{\max } & \mathrm{f}^{\prime}<\mathrm{f}_{\mathrm{avg}}
\end{array}\right. \\
& \mathrm{pm}=\left\{\begin{array}{cl}
\mathrm{pm}_{\max }-\frac{\left(\mathrm{pm}_{\max }-\mathrm{pm}_{\min }\right)\left(\mathrm{f}_{\max }-\mathrm{f}\right)}{\mathrm{f}_{\max }-\mathrm{f}_{\text {avg }}}, & \mathrm{f} \geq \mathrm{f}_{\text {avg }} \\
\mathrm{pm}_{\text {max }}{ }^{\prime} & \mathrm{f}<\mathrm{f}_{\text {avg }}
\end{array}\right.
\end{aligned}
$$

where, $\mathrm{p} c_{\max }, \mathrm{pc}_{\min }, \mathrm{pm}_{\max }$ and $\mathrm{pm}_{\min }$ are the maximum, minimum crossover rate and mutation rate, respectively. $f_{\max }, f_{a v g}$ are the maximum fitness value and the average fitness for each generation of population. $\mathrm{f}^{\prime}$ is the larger fitness value of the two individuals to cross, and $\mathrm{f}$ is the fitness value of the variant individuals.

Firstly, the chromosome was constructed by a binary encoding of the initial threshold and weight of the neural network, and the prediction error of the neural network was used as our fitness value. Then the individual difference was produced by chromosomal variation and cross, and the selection of the wheel was executed by the principle of survival of the fittest.

The optimal threshold and weight of the neural network were found. Finally, based on these parameters, the neural network was trained to get the best network model.

\subsection{Neural Network Optimized by Adaptive Genetic Algorithm Based on Kerf Angle}

It was finally determined that the structure of ANN is 4-11-1, that is, with 4 input nodes, 11 hidden nodes and 1 output nodes. The adaptive genetic algorithm parameters included, the population size is 24 , the maximum cross rate is 0.7 , the minimum cross rate is 0.1 , the maximum mutation rate is 0.05 , and the minimum mutation rate is 0.01 . Similarly, the 22 sets of data selected above were used for training. A neural network prediction model with high accuracy was established by MATLAB 2016. 
The structure of the neural network is shown in Figure 7. The regression performance of the neural network is shown in Figure 8.

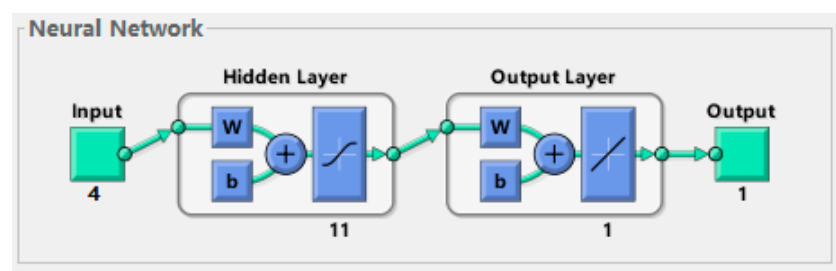

Figure 7. ANN's (BP-AGA) structure diagram.
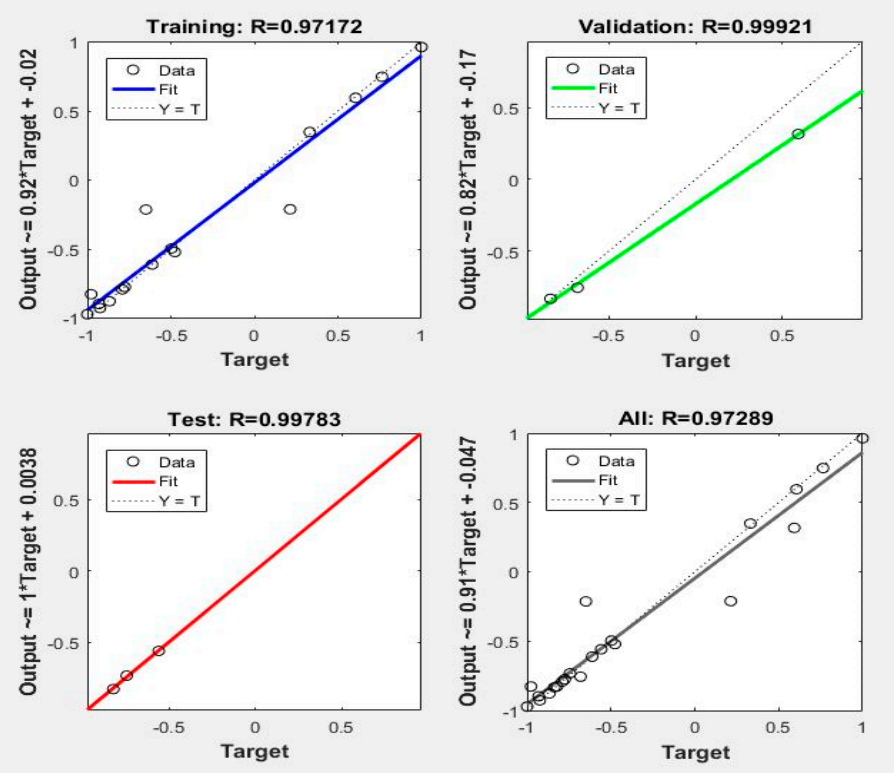

Figure 8. ANN'S (BP-AGA) regression performance diagram.

From Figure 8, it can be found that the multivariate correlation coefficient $\mathrm{R}$ of training and testing is 0.97172 and 0.99783 , respectively, with a high goodness of fit, listed in the Table 4 . Then, the remaining three groups are still used as checking groups, which are calculated by the statistical formulae $\mathrm{R}^{2}$, MSE and MAPE. The results are listed into the Table 5.

\section{Comparison of the Two Analysis Methods}

Currently, the main common methods for multivariate regression analysis are Forward, Forward, Backward and Stepwise. But in most cases, they are difficult to fit and are prone to multiple collinear troubles [24]. Therefore, a large amount of time has to be used to perform various transformations on the data to obtain a higher coefficient of multiple correlation and determination.

However, using the artificial neural network to learn experimental data, and then predicting, only the optimization algorithm is needed to optimize the initial threshold and weight of the network, and then the simple network structure parameter adjustment can achieve the purpose.

From Tables 4 and 5, the fitting quality and prediction performance of the regression model are not as good as the training quality and prediction performance of neural network model. Moreover, compared with the statistical analysis results of training quality and prediction performance, it can be seen that the neural network has better robustness and fault tolerance than the fitting regression method. 
Table 4. Fitting or Training quality performance.

\begin{tabular}{cccc}
\hline \multirow{2}{*}{ Model } & \multicolumn{3}{c}{ Fitting or Training Quality } \\
\cline { 2 - 4 } & MSE & MAPE (\%) & $\mathbf{R}^{\mathbf{2}}$ \\
\hline Regression & 0.3647 & 19.5027 & 0.9558 \\
network & 0.0987 & 6.0343 & 0.9881 \\
\hline
\end{tabular}

Table 5. Prediction quality.

\begin{tabular}{ccccccc}
\hline \multirow{2}{*}{ Model } & \multicolumn{3}{c}{ Number } & \multicolumn{3}{c}{ Prediction Quality } \\
\cline { 2 - 7 } & $\mathbf{1 8}$ & $\mathbf{2 2}$ & $\mathbf{2 4}$ & MSE & MAPE (\%) & $\mathbf{R}^{\mathbf{2}}$ \\
\hline Regression & 1.9460 & 2.0897 & 1.9359 & 0.6415 & 69.4384 & 0.8383 \\
network & 1.8161 & 1.2147 & 0.8946 & 0.0039 & 5.4244 & 0.9979 \\
experiment & 1.7973 & 1.2859 & 0.8156 & & & \\
\hline
\end{tabular}

\section{The Integrated SA-BP-AGA Optimization}

Based on the trained neural network prediction model, a simulated annealing algorithm was used to find the optimal parameter combination of the minimum processing kerf angle. The integrated SA-BP-AGA of the above description is shown in Figure 9.

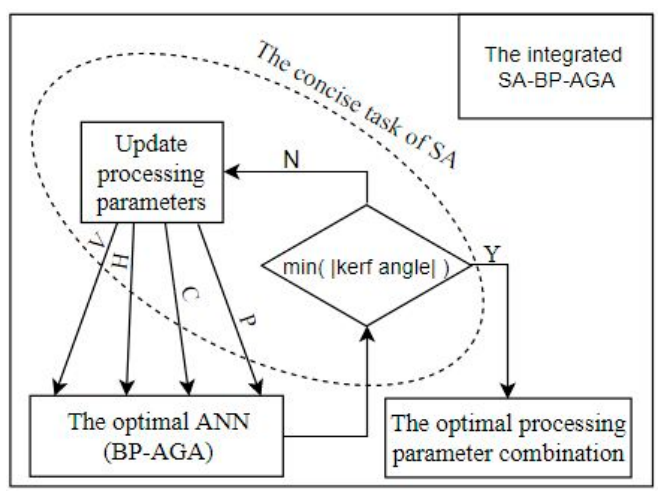

Figure 9. SA-BP-AGA structure schematic diagram.

The simulated annealing algorithm is a random search technique that is able to escape local optima using a probability function [25]. SA is a relatively mature algorithm, widely used in VLSI (Very Large Scale Integration) design, image recognition and neural network computer research. It can be decomposed into three parts: Solution space, objective function and initial solution. Here, the solution space is composed of the ranges of various processing variables. The objective function is the AGA-optimized neural network, and the initial solution is set as the best parameter group that appears in the experiment, which is the 24th in the Table 3. The optimal solutions of the MATLAB Optimization Toolbox is given in Figure 10 on the base of these criteria as listed in Table 6.

Table 6. Combination of simulated annealing (SA) parameter rates.

\begin{tabular}{cc}
\hline Parameters & Setting Value/Function Type \\
\hline Objective limit & $1 \times 10^{-4}$ \\
Annealing function & Boltzmann annealing \\
Reannealing interval & 100 \\
Temperature update function & Exponential temperature \\
Initial temperature & 100 \\
Acceptance probability function & Simulated annealing acceptance \\
Data type & Double \\
\hline
\end{tabular}


As shown in Figure 10, the theoretically optimal solution was observed that the minimum kerf angle is $6.9425 \times 10^{-5}$. The set value of process parameters that lead to the minimum $\theta$ value are $31.5 \mathrm{~mm} / \mathrm{min}$ for traverse speed, $0.7806 \mathrm{~mm}$ for standoff distance, $0.07841 \%$ for slurry concentration and $33.73 \mathrm{MPa}$ for jet pressure.

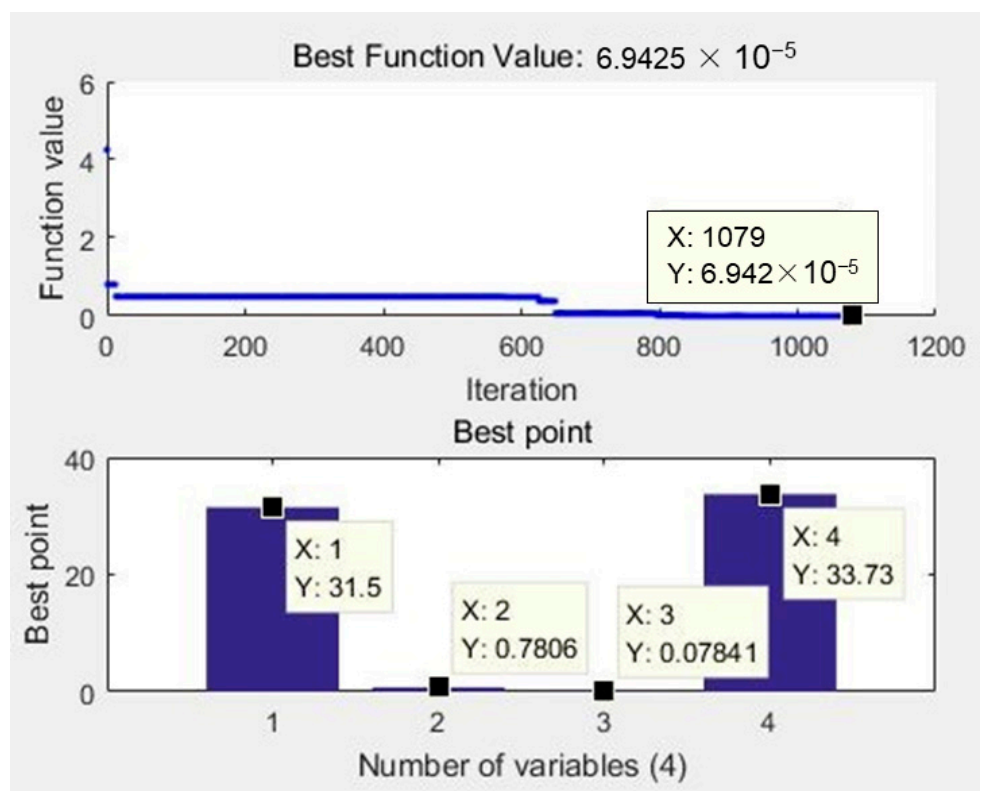

Figure 10. Fitness function plot of SA-BP-AGA.

\section{Conclusions}

The paper carried out experiments according to Taguchi's orthogonal method, and established two predictive models for kerf taper based on a multivariate nonlinear model and the BP-AGA model. Meanwhile, statistical formulae (MAPE, MSE and $\mathrm{R}^{2}$ ) were used to verify and compare the reliability of the two prediction models. The BP-AGA prediction model is more reliable than the multivariate nonlinear regression prediction model. Moreover, neural network prediction shows better robustness and fault tolerance. The main influencing factors can be determined by the retardation coefficient proposed in this paper. This coefficient proposes to broaden the application of the Taguchi orthogonal test method in the field of the non-precision control industry, and provides a solution for the study of fluctuation factors by the Taguchi orthogonal horizontal experiment method. It was found that the main factor affecting the kerf angle is slurry concentration, and then the system pressure and standoff distance, while the traverse speed has barely influence. The optimal processing parameter combination under the condition of the minimal kerf angle are obtained by SA based on the prediction model of BP-AGA. The study results can improve the performance for TC18 machining by ASJ and guide actual production.

Author Contributions: Conceptualization, J.L. and C.G.; methodology, J.L.; software, J.L.; validation, J.L., X.Z. and F.W.; formal analysis, J.L.; investigation, J.L.; resources, C.G.; data curation, Q.X.; writing-original draft preparation, J.L.; writing-review and editing, J.L. and C.G; visualization, J.L.; supervision, C.G.; project administration, C.G and J.L.; funding acquisition, C.G.

Funding: This work was funded by the Fundamental Research Funds for the Central Universities (2017XKZD02).

Conflicts of Interest: The authors declare no conflict of interest. 


\section{References}

1. Ulutan, D.; Ozel, T. Machining induced surface integrity in Titanium and Nickel Alloys: A review. Int. J. Mach. Tool Manuf. 2011, 51, 250-280. [CrossRef]

2. Boyer, P.R.; Briggs, R.D. The use of $\beta$ Titanium Alloys in the Aerospace Industry. J. Mater. Eng. Perform. 2005, 14, 681-685. [CrossRef]

3. Vargas Pérez, R.G. Wear mechanisms of WC inserts on face milling of gamma titanium aluminides. Wear 2005, 259, 1160-1167. [CrossRef]

4. Mitchell, A. Melting, Casting and forging problems in titanium alloys. Mater. Sci. Eng. 1998, 243, $257-262$. [CrossRef]

5. Lei, S.T.; Liu, W.J. High-speed machining of titanium alloys using the driven rotary tool. Int. J. Mach. Tool Manuf. 2002, 42, 653-661. [CrossRef]

6. Nabhani, F. Machining of aerospace titanium alloys. Robot. Comput. Integr. Manuf. 2001, 17, 99-106. [CrossRef]

7. Novovic, D.; Dewes, R.C. The effect of machined topography and integrity on fatigue life. Int. J. Mach. Tool Manuf. 2004, 44, 125-134. [CrossRef]

8. Che-Haron, C.H. Tool life and surface integrity in turning titanium alloy. J. Mater. Process. Technol. 2001, 118, 231-237. [CrossRef]

9. Wang, J.J.; Guo, H.Z.; Liang, H.Q.; Zhao, Z.L. Study of TC18 alloy forging process parameters based on BP neural network. Hot Working Technol. 2014, 43, 1-6.

10. Liu, X.Z.; Tao, H.; Li, M.W. Optimization of parameters for milling titanium alloy TC18 with improve genetic algorithm. Modul. Mach. Tool Autom. Manuf. Tech. 2010, 5, 41-43.

11. Qi, H.; Wen, D.H.; Yuan, Q.L. Numerical investigation on particle influence erosion in ultrasonic-assisted abrasive slurry jet micro-machining of glasses. Powder Technol. 2017, 314, 627-634. [CrossRef]

12. Wang, J.; Kuriyagawa, T.; Huang, C. An experimental study to enhance the cutting performance in abrasive waterjet machining. Mach. Sci. Technol. 2003, 7, 191-207. [CrossRef]

13. Aznrir, M.A.; Ahsan, A.K. A study of abrasive water jet machining process on glass/epoxy composite laminate. J. Mater. Process. Technol. 2009, 209, 6168-6173. [CrossRef]

14. Alberdi, A.; Rivero, A.; Lacalle, L.N.L. Effect of process parameter on the kerf geometry in abrasive water jet milling. Int. J. Adv. Manuf. Technol. 2010, 5, 467-480. [CrossRef]

15. Feng, D.C.; Shi, L.L.; Guo, C.W.; Wang, F.C.; Chen, Y.Q. Numerical and experimental study on the flow characteristics of abrasive slurry jet with polymer additives. Int. J. Adv. Manuf. Technol. 2018, 95, 3289-3299. [CrossRef]

16. Wang, F.C.; Xu, Q.W.; Feng, D.C.; Guo, C.W. Experiment study on performance of abrasive slurry jet with or without high polymer in stainless steel machining. Int. J. Adv. Manuf. Technol. 2018, 95, 2449-2456. [CrossRef]

17. Wojciechowski, S.; Maruda, R.W.; Krolczyk, G.M.; Niesłony, P. Application of signal to noise ratio and grey relational analysis to minimize forces and vibrations during precise ball end milling. Precis. Eng. 2017, 51, 582-596. [CrossRef]

18. Karabulut, S. Optimization of surface roughness and cutting force during $\mathrm{AA} 7039 / \mathrm{Al}_{2} \mathrm{O}_{3}$ metal matrix composites milling using neural networks and Taguchi method. Measurement 2015, 66, 139-149. [CrossRef]

19. Wojciechowski, S.; Maruda, R.W.; Barrans, S.; Nieslony, P.; Krolczyk, G.M. Optimisation of machining parameters during ball end milling of hardened steel with various surface inclinations. Measurement 2017, 111, 18-28. [CrossRef]

20. Azlan, M.Z.; Habibollah, H.; Safian, S. Optimization of process parameters in the abrasive waterjet machining using integrated SA-GA. Appl. Soft Comput. 2010, 11, 5350-5359. [CrossRef]

21. Srinivasu, D.S.; Ramesh, B.N. A neuro-genetic approach for selection of process parameters in abrasive waterjet cutting considering variation in diameter of focusing nozzle. Appl. Soft Comput. 2008, 8, 809-819. [CrossRef]

22. Durakbasa, M.N.; Akdogan, A.; Vanli, A.S.; Bulutsuz, A.G. Optimization of end milling parameters and determination of the effects of edge profile for high surface quality of AISI H13 steel by using precise and fast measurements. Measurement 2015, 68, 92-99. [CrossRef] 
23. Caydas, U.; Hascalik, A. A study on surface roughness in abrasive waterjet machining process using artificial neural networks and regression analysis method. J. Mater. Process. Technol. 2008, 202, 574-582. [CrossRef]

24. Wibowo, A. Hybrid kernel principal component regression and penalty strategy of multiple adaptive genetic algorithms for estimating optimum parameters in abrasive waterjet machining. Appl. Soft Comput. 2018, 62, 1102-1112. [CrossRef]

25. Steinbrunn, M.; Moerkotte, G.; Kemper, A. Heuristic and randomized optimization for the Join Ordering Problem. VLDB J. 1997, 6, 8-17. [CrossRef]

(C) 2019 by the authors. Licensee MDPI, Basel, Switzerland. This article is an open access article distributed under the terms and conditions of the Creative Commons Attribution (CC BY) license (http://creativecommons.org/licenses/by/4.0/). 